\title{
VATS lobectomy: does surgical heterogeneity prevent evidence on pain control?
}

\author{
Luigi Santambrogio ${ }^{1,2}$, Valeria Musso ${ }^{1,2}$ \\ ${ }^{1}$ Thoracic Surgery and Lung Transplantation Unit, Fondazione IRCCS Ca' Granda-Ospedale Maggiore Policlinico of Milan, Milan, Italy; \\ ${ }^{2}$ Department of Pathophysiology and Transplantation, University of Milan, Milan, Italy \\ Correspondence to: Professor Luigi Santambrogio. Thoracic Surgery and Lung Transplantation Unit, Fondazione IRCCS Ca' Granda-Ospedale \\ Maggiore Policlinico of Milan, via Francesco Sforza, 35, 20122 Milan, Italy. Email: luigi.santambrogio@unimi.it. \\ Provenance: This is an invited Editorial commissioned by the Section Editor Laura Chiara Guglielmetti (University Hospital Zurich, Zurich, \\ Switzerland). \\ Comment on: Umari M, Carpanese V, Moro V, et al. Postoperative analgesia after pulmonary resection with a focus on video-assisted thoracoscopic \\ surgery. Eur J Cardiothorac Surg 2017.[Epub ahead of print].
}

Submitted Mar 20, 2018. Accepted for publication Mar 26, 2018.

doi: $10.21037 /$ jtd.2018.03.189

View this article at: http://dx.doi.org/10.21037/jtd.2018.03.189

VATS lobectomy was first described as a surgical treatment for lung cancer about 25 years ago (1); after initial scepticism concerning it, VATS technique has progressively spread in many centers worldwide.

Nowadays, scientific societies indicate mini-invasive techniques as the preferred approach compared to traditional thoracotomy, and VATS lobectomy as the therapeutic first choice recommended in experienced centres (2).

Nevertheless, VATS lobectomy has had slow adoption, even though the percentage of VATS lobectomies performed is increasing, reaching different rates from one country to another and even from one centre to another in the same country. VATS lobectomy adoption achieves a percentage of $30-40 \%$ in the USA (3), whilst, according to the ESTS database, whose data are collected on voluntary basis, it is $30 \%$ in Europe (4), 29\% in Great Britain and Ireland (5), 65\% in Denmark (6), and 46\% in Italy (7).

The reason behind this low percentage does not seem to be the higher equipment costs, nor the characteristics of the centre in which the surgery is performed; it is probably due to the subjective preference of the surgeon or to the presence of a VATS lobectomy institutional program.

Surgeons' individual background and education, and consequently their familiarity with VATS lobectomy, affects their tendency to choose VATS over thoracotomy. Surgeon specialty training is also associated with VATS usage: the number of VATS lobectomy performed has increased significantly more among thoracic surgeons than among cardiothoracic and general surgeons $(8,9)$.

The incessant technical evolution in VATS lobectomy, supported by the industries that continue producing better and more dedicated instruments, has led to the development of (theoretically) less and less invasive approaches: from four- to tri- to bi- to uniportal VATS, and from a $6-7 \mathrm{~cm}$ to a 3-4 cm utility mini-thoracotomy $(10,11)$. The approach of choice obviously depends on personal experience, on the learning curve and the surgeon case volume too.

Minimally-invasive surgery represents a major change in the history of surgery, especially in thoracic surgery, in which post-operative pain always occurs and often plays an important role in the recovery process. Mini-invasive techniques allow to decrease soft-tissue trauma, with less damage to the chest wall by avoiding the use of rib retractors, thus reducing the likelihood of rib, periosteum and, above all, intercostal nerve injury. In patients undergoing VATS procedures, persistent post-thoracotomy pain is also less likely to occur than after open thoracotomy $(12,13)$.

Still, pain ensues from VATS lobectomy too, even though it is less relevant than in patients undergoing open surgery, and its intensity is not always related to the severity of surgical trauma.

Many interesting articles and reviews can be found about post-operative pain after VATS lobectomy and its management, but only few are randomized and many 
are often based on a limited number of patients, making it difficult to draw practical conclusions and to write guidelines.

In their article, Umari et al. (14) carried out a very careful and complete review of the literature, and in the end she emphasized the most important aspects of the current indications for analgesia, such as the greater effectiveness of a multi-modal analgesic approach, based on: the use of loco-regional analgesia, with paravertebral block as a first choice compared to thoracic epidural analgesia (TEA); the use of pharmacologic therapy (paracetamol, NSAIDs, weak opioids, etc.).

The purpose of this approach is to relieve the pain and avoid the use of TEA and strong opioids, in order to reduce the occurrence of their adverse effects such as nausea and vomit, headache, arterial hypotension, urinary bladder retention, lower limbs motor paralysis and epidural hematoma.

In the transition from thoracotomy to VATS lobectomy, many centres continued using the same protocol for the management of intra- and post-operative pain: TEA used to be the analgesic gold standard for open thoracic surgery, but it is clear that the use of TEA minimizes the benefits of a technique associated with less post-operative pain (15-19).

The term "VATS lobectomy" includes a broad range of surgical procedures: the number of ports, the extent of the incision, the presence of pleural adhesions and the technical difficulties affect the duration of surgery and therefore of anesthesia. It obviously takes surgeons in training more time to perform VATS procedures, especially when they are testing less invasive techniques such as uniportal VATS lobectomy. In this approach, three or four surgical instruments are inserted through a single 3 to $5 \mathrm{~cm}$ incision, with a higher risk of applying great pressure on the wound edges for a significant amount of time: this explains why, when performed by a surgeon with less experience, uniportal VATS lobectomy can be associated with more post-operative pain. Therefore, surgeons' competence and case volume play an important role in the occurrence of post-operative pain.

Patients' characteristics are also a factor that should always be considered. Pain is probably the most subjective symptom, and its onset, duration and severity are often unpredictable.

Umari et al. well summarized all the analgesic techniques and their combination, but in addition to this I would add what I believe is a fundamental step, namely, that before undergoing surgery the patient is given information about post-operative pain and how it will be managed. It is also important that a physiotherapist does a thorough assessment of the patient in the pre-operative phase, so that it will be easier to work together in the post-operative stage. The physiotherapist, in fact, will be the first one to work with patients after surgery and will be causing them pain by mobilizing them $(20,21)$. Finally, preventive analgesia should be considered an additional tool to anticipate the central sensitization $(22,23)$.

Post-operative pain, besides causing discomfort to the patient, can also lead to severe complications. Excessive pain after surgery induces a reduction in lung volumes and diaphragm excursion, can delay mobility and prevent coughing. All these factors can bring about complications such as pulmonary infections, cardiac arrhythmia and embolism; patients unable to mobilise are at higher risk of developing these complications (24).

The combination of loco-regional analgesia with paravertebral block and pharmacologic therapy with fewer adverse effects seems ideal, because it relieves pain immediately after surgery, thus enabling patients to mobilise earlier after the surgical procedure.

In a recently published editorial, Decaluwé (25) discussed the spreading of VATS lobectomy and, above all, the technological development which occurred in the last 5 years that led to the search for "ultra-minimally invasive resections". According to Decaluwé, it is quite difficult to give an opinion on the pursuit for ultimate minimal invasiveness in order to reduce pain. Some authors even described VATS lobectomies in non-intubated patients (10). Surely, larger randomized trials are needed to obtain hard objective data about meaningful pain reduction in patients undergoing minimally-invasive VATS lobectomy, but the surgical community should also focus on other priorities, like promoting safe surgery and stimulating oncologic quality of resection.

\section{Acknowledgements}

None.

\section{Footnote}

Conflicts of Interest: The authors have no conflicts of interest to declare.

\section{References}

1. Roviaro G, Rebuffat C, Varoli F, et al. Videoendoscopic pulmonary lobectomy for cancer. Surg Laparosc Endosc 1992;2:244-7. 
2. Howington JA, Blum MG, Chang AC, et al. Treatment of stage I and II non-small cell lung cancer: Diagnosis and management of lung cancer, 3rd ed: American College of Chest Physicians evidence-based clinical practice guidelines. Chest 2013;143:e278S-e313S.

3. Abdelsattar ZM, Allen MS, Shen KR, et al. Variation in Hospital Adoption Rates of Video-Assisted Thoracoscopic Lobectomy for Lung Cancer and the Effect on Outcomes. Ann Thorac Surg 2017;103:454-60.

4. ESTS database report. Available online: http://www.ests. org/collaboration/database_reports.aspx

5. Society of Cardiothoracic Surgery Report. Available online: http://scts.org/outcomes/thoracic

6. Jakobsen E, Rasmussen TR. The Danish Lung Cancer Registry. Clin Epidemiol 2016;8:537-41.

7. VATS group Italian Registry. Available online: http:// vatsgroup.org

8. Blasberg JD, Seder CW, Leverson G, et al. Video-Assisted Thoracoscopic Lobectomy for Lung Cancer: Current Practice Patterns and Predictors of Adoption. Ann Thorac Surg 2016;102:1854-62.

9. Tchouta LN, Park HS, Boffa DJ, et al. Hospital Volume and Outcomes of Robot-Assisted Lobectomies. Chest 2017;151:329-39.

10. Gonzalez-Rivas D, Yang Y, Guido W, et al. Nonintubated (tubeless) uniportal video-assisted thoracoscopic lobectomy. Ann Cardiothorac Surg 2016;5:151-3.

11. Perna V, Carvajal AF, Torrecilla JA, et al. Uniportal videoassisted thoracoscopic lobectomy versus other videoassisted thoracoscopic lobectomy techniques: a randomized study. Eur J Cardiothorac Surg 2016;50:411-5.

12. McElnay PJ, Molyneux M, Krishnadas R, et al. Pain and recovery are comparable after either uniportal or multiport video-assisted thoracoscopic lobectomy: An observation study. Eur J Cardiothorac Surg 2015;47:912-5.

13. Shanthanna H, Aboutouk D, Poon E, et al. A retrospective study of open thoracotomies versus thoracoscopic surgeries for persistent postthoracotomy pain. J Clin Anesth 2016;35:215-20.

14. Umari M, Carpanese V, Moro V, et al. Postoperative analgesia after pulmonary resection with a focus on video- assisted thoracoscopic surgery. Eur J Cardiothorac Surg 2017. [Epub ahead of print].

15. Wildgaard K, Petersen RH, Hansen HJ, et al. Multimodal analgesic treatment in video-assisted thoracic surgery lobectomy using an intraoperative intercostal catheter. Eur J Cardiothorac Surg 2012;41:1072-7.

16. Kosiński S, Fryźlewicz E, Wiłkojć M, et al. Comparison of continuous epidural block and continuous paravertebral block in postoperative analgaesia after video-assisted thoracoscopic surgery lobectomy: a randomised, noninferiority trial. Anaesthesiol Intensive Ther 2016;48:280-7.

17. Kamiyoshihara, M, Nagashima, T, Ibe, T, et al. Is epidural analgesia necessary after video-assisted thoracoscopic lobectomy? Asian Cardiovasc Thorac Ann 2010;18:464-8.

18. Obuchi T, Yoshida Y, Moroga T, et al. Postoperative pain in thoracic surgery: re-evaluating the benefits of VATS when coupled with epidural analgesia. J Thorac Dis 2017;9:4347-52.

19. Piccioni F, Ragazzi R. Anesthesia and analgesia: how does the role of anesthetists changes in the ERAS program for VATS lobectomy. J Vis Surg 2018;4:9.

20. Holm J, Licht PB. Editorial on pain following thoracic surgery. J Thorac Dis 2017;9:3545-6.

21. Bayman EO, Parekh KR, Keech J, et al. Response to "VATS vs. thoracotomy regarding postoperative chronic pain". J Thorac Dis 2017;9:E1151-3.

22. Nosotti M, Rosso L, Tosi D, et al. Preventive analgesia in thoracic surgery: controlled, randomized, double-blinded study. Eur J Cardiothorac Surg 2015;48:428-33.

23. Yang HC, Lee JY, Ahn S, et al. Pain control of thoracoscopic major pulmonary resection: is pre-emptive local bupivacaine injection able to replace the intravenous patient controlled analgesia? J Thorac Dis 2015;7:1960-9.

24. LoMauro A, Aliverti A, Chiesa M, et al. Ribcage kinematics during exercise justifies thoracoscopic versus postero-lateral thoracotomy lobectomy prompt recovery. Eur J Cardiothorac Surg 2017;52:1197-205.

25. Decaluwé H. One, two, three or four ports... does it matter? Priorities in lung cancer surgery. J Thorac Dis 2016;8:E1704-8.
Cite this article as: Santambrogio L, Musso V. VATS lobectomy: does surgical heterogeneity prevent evidence on pain control? J Thorac Dis 2018;10(Suppl 9):S1029-S1031. doi: 10.21037/jtd.2018.03.189 